\title{
Intention to Eat Traditional Food among Boys and Girls in Malaysia
}

\author{
Nur Hafizah Muhammad, Muhammad Shahrim Ab. Karim, and Humairah Hamzah
}

\begin{abstract}
Traditional foods serve as representation of culture and tradition of a country and are passed from one generation to another. The cuisines are prepared using fresh ingredients containing beneficial nutrients which protect human body from food-related diseases. Unfortunately, in this modern environment, adolescents nowadays seem to consume less traditional food compared to their ancestors due to various factors. This study investigates the differences in terms of intention to eat traditional food between boys and girls in Malaysia. 655 samples were drawn from Selangor's secondary school students aged between 15 to 18 years old. Results showed that girls are more traditionally oriented as they chose traditional food as their meals compared to boys. Moreover, urban adolescents appear to have higher intention to eat traditional food compared to rural adolescents.
\end{abstract}

Index Terms-Adolescents, intention to eat, Malaysia traditional food, urban and rural area.

\section{INTRODUCTION}

Malaysia is one of the exquisite countries in Southeast Asia that offers mouthwatering traditional food created by the multi-ethnic groups that have lived together for centuries [1]. There are varieties of traditional delicacies such as the famous "Nasi lemak", "Roti canai", "Bak kut teh", white coffee and "teh tarik" which are usually mentioned widely across Malaysia. In history, Malaysian traditional foods are creatively made by the finest and fresh found ingredients surrounding the neighbourhood and later the recipes are being passed down to younger generations [2]. European Commission defines traditional food as food with special characteristics and distintively unique from other similar food, particularly in the usage of 'traditional ingredients' and 'traditional production methods' [3] (p. 1).

Furthermore, traditional food not only provide good source of balanced nutrients for the body, it also portrays the cultures and traditions of a country [4] and therefore, it is an obligation for the Malaysians to safeguard the food from extinction in the future.

Unfortunately, the modern world has exposed the younger generations to other collection of foods such as Western fast food, Japanese food and many more and our traditional food is not in any of the options. Reference [5] explained that some

Manuscript received January 21, 2014; revised March 16, 2014. This work was supported in part by the Department of Food Service and Management, Faculty of Food Science and Technology, Universiti Putra Malaysia (UPM).

N. H. Muhammad is with the Universiti Malaysia Kelantan, 16100 Pengkalan Chepa, Kelantan, Malaysia (e-mail: izzah_8987@yahoo.com).

M. S. Ab Karim and H. Hamzah are with Universiti Putra Malaysia, 43400 Serdang, Selangor, Malaysia (e-mail: shahrim@upm.edu.my). adolescents do not eat traditional food as much as Amerian fast food and some of them are ashamed to bring traditional food to school. The same goes to Malaysian adolescents, they often tend to choose Western fast food and junk food as their meals, rather than choosing traditional food [6].

There are various factors that influence the adolescents' choices of foods. Besides food availability and their place of living, gender is known as one of the main determinants in shaping a person's eating behavior. Researchers revealed that girls are more health conscious and concern more on appearance compared to boys [3]. At home, they are introduced to the traditional food while assisting their mothers to prepare family meals, meanwhile boys usually lend their hands during festive seasons' food preparation process [7], [8]. On the other hand, reference [9] argued that girls are less traditionally oriented than boys in terms of eating behavior. They like to consume more snacks and non-traditional food to satisfy their appetite. However, it is proven that there are no differences in terms of gender regarding Western fast food consumptions. Both girls and boys enjoy eating the food equally [10].

The current study on tourists' perception on traditional food has been a point of interest among researchers, however, this study aims to put valuable inputs for the literature from the Malaysian adolescents' perspective. In specific, this study addresses two objectives: (1) To investigate the intention to eat traditional food between girls and boys and (2) To examine the difference in terms of the intention to eat traditional food among rural and urban adolescents.

\section{Methodology}

\section{A. Sample and Population}

Adolescents aged between 15 to 18 years old are eligible to participate in this cross-sectional study. With approval from the Ministry of Education, 700 adolescents from 8 public secondary schools in the state of Selangor were chosen as participants for this study. Due to geographical consideration, the area of Selangor was divided into four clusters: west, east, north and south areas. The questionnaires were distributed equally in each area according to the population proportion given by the Malaysian Census Department 2010.

Official permission letters were issued to the school principles prior distributing the questionnaires to the adolescents. After that, assigned teachers escorted the researchers to the classroom to pass over the survey forms. To avoid bias results, teachers and researchers were not allowed to be present when the students answered the questionnaire. As a token of appreciation, ball pens were 
given to the students at the end of session.

\section{B. Survey Instrument}

Theory of Planned Behavior (TPB) variables employ as the backbone of the self-administered questionnaire development process. The TPB is widely used in the determinants identification in other food consumptions such as fruit, vegetables and dairy products consumptions [11]. Basically, the questionnaire comprises of 5 sections. Section (A) contains 21 items for attitudes towards traditional food, Section (B) contains 16 items for social norms and Section (C) contains 17 items for perceived behavioral control (PBC) as the independent variables to determine the adolescents' intention to eat traditional food, while 5 items in Section (D) verify the intentions of the adolescents and Section (E) notes the demographic profile of the participants. Table I below shows the reliability results (Cronbach's alpha) for 4 major variables used. All results are above 0.7 .

TABLE I: RELIABILITY TEST RESULTS

\begin{tabular}{lcc}
\hline \hline Sections & Items & Reliability \\
\hline A: Attitudes towards traditional food & 21 & 0.85 \\
B: Social norms & 16 & 0.89 \\
C: PBC & 17 & 0.84 \\
D: Intention to eat traditional food & 5 & 0.86 \\
\hline \hline
\end{tabular}

\section{Data Analysis}

Out of the 700 questionnaires given, only 655 were usable for further analysis. The data was analyzed using SPSS version 20. Multiple linear regressions (MLR) was used to test the contributions of each of the variables in predicting the intentions to eat traditional food among the adolescents.

\section{RESULTS AND DISCUSSIONS}

\section{A. Profile of Participants}

Table II shows the frequency of boys and girls from both rural and urban areas. About $37.2 \%$ of girls and $62.8 \%$ of boys come from the urban area; meanwhile about $57.2 \%$ of girls and $42.8 \%$ of boys live in the rural area. Most urban participants come from high socioeconomic family with monthly household income of more than RM 4,000 (25.9\%) compared to only 45 participants in the rural area as most of their family's household income are less than RM 1999, which is approximately $41.6 \%$. Besides that, $21.2 \%$ of the urban participants and $28.4 \%$ of the rural participants are from medium socioeconomic families with household income between RM 2,000 - RM 2,999. As well as, $13.0 \%$ and $11.7 \%$ of the urban participants, plus $10.6 \%$ and $4.6 \%$ of the rural participants are also in the medium socioeconomic families' category with income between RM 3,000 - RM 3,499 and RM 3,500 - RM 3,999, respectively.

In the current Malaysian situation, parents of the adolescents living in the city are both working. With hectic metropolitan life, the parents went off to work early in the morning and returned home at night. On the other hand, mothers from rural areas are working as full-time housewives and their husbands are the breadwinner [12]. This may be explained by the different percentage of household incomes in the Table II below.

TABLE II: DEMOGRAPHIC PROFILE OF PARTICIPANTS

\begin{tabular}{lcc}
\hline \hline Demographic profile & Urban (\%) & Rural (\%) \\
\hline Gender & & \\
Girl & 37.2 & 57.2 \\
Boy & 62.8 & 42.8 \\
Household income & & \\
Below RM 1,999 & 28.2 & 41.6 \\
RM 2,000 - RM 2,999 & 21.2 & 28.4 \\
RM 3,000 - RM 3,499 & 13.0 & 10.6 \\
RM 3,500 - RM 3,999 & 11.7 & 4.6 \\
More than RM 4,000 & 25.9 & 14.9 \\
\hline \hline
\end{tabular}

\section{B. Intention to Eat Traditional Food between Boys and Girls}

As mentioned previously, gender is one of the factors that might influence someone's food choices, especially the adolescents. During the period of adolescence, healthy food intake is very crucial for both boys and girls because it may affect their education performance and might invite food-related diseases if they consume unhealthy food excessively [13].

Table III- Table VI represent the regression results for the adolescents' intentions to eat traditional food. The results imply significant differences between boys and girls on their intention to eat traditional food. For both urban and rural areas, girls' $R^{2}$ showed higher than boys'. The value of $R^{2}$ is 0.47 for girls in rural area and 0.46 for the boys, which explain attitudes, social influence and controllability account $47 \%$ and $46 \%$ variations in their intentions to eat traditional food. Nonetheless, girls from city area showed 0.54 of $R^{2}$ value and 0.50 for boys', which means the three predictors account about $54 \%$ for girls' and $50 \%$ for boys' intention to consume traditional food. As an overall, there are positive correlations between the predictors and the adolescents' intentions.

\section{Intention to Eat Traditional Food in Rural Area}

Focusing on Table III and Table IV, the perceived behavioral control (PBC) variables contribute the most for the variance of percentage for both genders in the rural area. The PBC variables are determinants in the TPB that indicate external and internal obstacles that a person perceives when engaging to a particular behavior, moreover, that person is able to choose whether to commit to the behavior or not after considering the barriers [11].

Furthermore, beta value for standardized coefficients clarified $(B=0.37)$ for girls and $(B=0.41)$ for boys. These interpret that as the PBC variables increase by one unit, the intention to eat traditional food will increase by 0.37 and also 0.41 units. This shows that boys are more able of controlling (after consideration the barriers) their own intention than girls in terms of eating traditional food. On the other hand, girls tend to be influenced by others, commonly from their parents. This may proved by the second contributor for the girls which is social norms variable $(B=0.32)$, where boys' attitude towards traditional food is the middle contributor which drives the intention $(B=0.27)$. Theoretically, social norms indicate the other parties' pressure, influencing the 
adolescents' decision to eat traditional food and their attitudes towards the food involving the overall evaluations towards them including knowledge, sensory evaluation, health concern and respect to culture and traditions [14]. Notably, girls are responsible for helping their mothers to prepare family meals, and in Malaysia, traditional foods are commonly served at home [15]. So, indirectly, girls are exposed to the traditional foods in their home kitchens rather than boys who seldomly helping the elders. Sooner or later, they might be influenced by their mothers during the foods' preparation. They may feel the enjoyment of cooking and eating traditional foods with their families which ultimately, make them intent to eat the foods [16].

\begin{tabular}{|c|c|c|c|c|c|}
\hline \multicolumn{6}{|c|}{ Rural } \\
\hline \multicolumn{6}{|c|}{ Girl } \\
\hline \multirow[t]{2}{*}{ Variables } & \multicolumn{2}{|c|}{$\begin{array}{c}\text { Unstandardized } \\
\text { coefficients }\end{array}$} & \multirow{2}{*}{$\begin{array}{c}\begin{array}{c}\text { Standardized } \\
\text { coefficients }\end{array} \\
\text { Beta }\end{array}$} & \multirow[t]{2}{*}{$t$} & \multirow[t]{2}{*}{ Sig. $t$} \\
\hline & Beta & Std. error & & & \\
\hline Constant & -0.18 & 0.38 & & -0.47 & 0.64 \\
\hline A & 0.24 & 0.12 & 0.14 & 2.04 & 0.04 \\
\hline B & 0.38 & 0.08 & 0.32 & 4.90 & 0.00 \\
\hline $\mathrm{C}$ & 0.50 & 0.09 & 0.37 & 5.40 & 0.00 \\
\hline \multicolumn{6}{|c|}{$F=51.58($ Sig. $=0.00)$} \\
\hline$R=0.68$ & $R^{2}=0.47$ & \multicolumn{4}{|c|}{ Adjusted $R^{2}=0.46$ Std. error $=0.49$} \\
\hline
\end{tabular}

\begin{tabular}{|c|c|c|c|c|c|}
\hline Dependen & REGRESSI & ION ANAL & $\begin{array}{l}\text { ditional food. } \\
\text { SIS OF BOYS IN }\end{array}$ & JRAL A & \\
\hline \multicolumn{6}{|c|}{ Rural } \\
\hline \multicolumn{6}{|c|}{ Boy } \\
\hline \multirow[t]{2}{*}{ Variables } & \multicolumn{2}{|c|}{$\begin{array}{l}\text { Unstandardized } \\
\text { coefficients }\end{array}$} & $\begin{array}{c}\text { Standardized } \\
\text { coefficients }\end{array}$ & \multirow[t]{2}{*}{$t$} & \multirow[t]{2}{*}{ Sig. $t$} \\
\hline & Beta & Std. error & Beta & & \\
\hline Constant & -0.14 & 0.40 & & -0.63 & 0.53 \\
\hline A & 0.40 & 0.11 & 0.27 & 3.52 & 0.00 \\
\hline B & 0.20 & 0.08 & 0.17 & 2.45 & 0.02 \\
\hline $\mathrm{C}$ & 0.52 & 0.10 & 0.41 & 4.43 & 0.00 \\
\hline \multicolumn{6}{|c|}{$F=37.54$ (Sig. $=0.00)$} \\
\hline$R=0.68$ & $R^{2}=0.46$ & \multicolumn{4}{|c|}{ Adjusted $R^{2}=0.45$ Std. error $=0.48$} \\
\hline
\end{tabular}

Dependent variable: Intention to eat traditional food.

\section{Intention to Eat Traditional Food in Urban Area}

As stated, Table V and Table VI signify the regression models for both genders of the adolescents. The tables show $54 \%$ of variances for girls and $50 \%$ for boys in their intentions to eat traditional food, and the variances can be predicted by the three independent variables. Contradictory to the rural adolescents, the $\mathrm{PBC}$ variables contribute the most for girls in the city area $(B=0.41)$, while only $(B=0.27)$ for the boys.

School activities such as cultural events and festive seasons' foods preparation may attract the boys to appreciate traditional foods more, in time, making them develop positive attitudes towards the foods [17], [18]. Moreover, reference [18] (p. 135), revealed that boys learn more effectively with hands-on approach. In general, knowledge and traditional lessons from school and informal education from home shape the adolescents' traditional food eating behavior.

However, social pressure shows no significant contribution to the urban adolescents (sig. $t>0.05$ ). Normally both parents of adolescents in the urban area are working and due to traffic congestions, their parents came home late. Hence, the parents will order take away meals for the family or let their children decide their own desired meals. Thus this scenario may cause social pressure to show no significant contribution to the urban adolescents [16].

TABLE V: REGRESSION ANALYSIS OF GIRLS IN URBAN AREA

\begin{tabular}{|c|c|c|c|c|c|}
\hline \multicolumn{6}{|c|}{ Urban } \\
\hline \multicolumn{6}{|c|}{ Girl } \\
\hline \multirow[t]{2}{*}{ Variables } & \multicolumn{2}{|c|}{$\begin{array}{l}\text { Unstandardized } \\
\text { coefficients }\end{array}$} & \multirow{2}{*}{$\begin{array}{c}\text { Standardized } \\
\text { coefficients }\end{array}$} & \multirow[t]{2}{*}{$t$} & \multirow[t]{2}{*}{ Sig. $t$} \\
\hline & Beta & Std. error & & & \\
\hline Constant & -0.39 & 0.39 & & -0.99 & 0.32 \\
\hline A & 0.44 & 0.13 & 0.28 & 3.37 & 0.00 \\
\hline B & 0.19 & 0.10 & 0.16 & 1.84 & 0.07 \\
\hline $\mathrm{C}$ & 0.55 & 0.11 & 0.41 & 4.93 & 0.00 \\
\hline \multicolumn{6}{|c|}{$F=44.96$ (Sig. $=0.00)$} \\
\hline$R=0.73$ & $R^{2}=0.54$ & \multicolumn{4}{|c|}{ Adjusted $R^{2}=0.52$ Std. error $=0.50$} \\
\hline
\end{tabular}

Dependent variable: Intention to eat traditional food

TABLE VI: REGRESSION ANALYSIS OF BOYS IN URBAN AREA

\begin{tabular}{|c|c|c|c|c|c|}
\hline \multicolumn{6}{|c|}{ Urban } \\
\hline \multicolumn{6}{|c|}{ Boy } \\
\hline \multirow[t]{2}{*}{ Variables } & \multicolumn{2}{|c|}{$\begin{array}{c}\text { Unstandardized } \\
\text { coefficients }\end{array}$} & \multirow{2}{*}{$\begin{array}{c}\begin{array}{c}\text { Standardized } \\
\text { coefficients }\end{array} \\
\text { Beta }\end{array}$} & \multirow[t]{2}{*}{$t$} & \multirow[t]{2}{*}{ Sig. $t$} \\
\hline & Beta & Std. error & & & \\
\hline Constant & -0.58 & 0.31 & & -1.88 & 0.06 \\
\hline A & 0.67 & 0.11 & 0.42 & 5.98 & 0.00 \\
\hline B & 0.14 & 0.08 & 0.11 & 1.63 & 0.10 \\
\hline $\mathrm{C}$ & 0.38 & 0.10 & 0.27 & 3.98 & 0.00 \\
\hline \multicolumn{6}{|c|}{$F=65.69($ Sig. $=0.00)$} \\
\hline$R=0.70$ & $R^{2}=0.50$ & \multicolumn{4}{|c|}{ Adjusted $R^{2}=0.49$ Std. error $=0.55$} \\
\hline
\end{tabular}

Dependent variable: Intention to eat traditional food

\section{E. The Differences between Rural and Urban Adolescents}

Surprisingly, the results disclose that the intention to eat traditional food among urban adolescents is higher than rural adolescents either girls or boys ( $R^{2}$ for both gender in urban area $>R^{2}$ for both gender in rural area). Albeit, rural area is synonym with traditional food industry and the foods are available all year long. They have been exposed to the traditional food since childhood and unfortunately, it seems that it is still not enough to further attract their intentions to eat traditional foods in the future [19]. An experiment done by reference [17] verified that rural adolescents tend to choose fast food over traditional food as they could have been persuaded by advertisements from television or internet.

On the other hand, urban adolescents are more open to insert new food in their daily meals. Albeit, they are introduced to modern food and other countries' traditional foods like Japanese food or Vietnamese food and are likely to consume higher intake of saturated fatty acid and energy densed food, they still prefer to eat the Malaysian traditional foods in the future [19].

\section{CONCLUSION}

Children should be trained to eat traditional foods since they are young, especially during adolescence period where they are trying to find their own identity by watching others surrounding them. Besides preserving the identity of the nation and containing multiple vitamins and minerals from 
the fresh ingredients used, eating traditional food is the major determinant for our younger generation's behaviors. Traditional cultures in Asia portray proper manners and well-being including ethics on how to eat traditional food [20]. This may be able to shape the attitudes of adolescents and generate a well-mannered community in this new millennium.

\section{ACKNOWLEDGMENT}

We would like to thank our lecturer for his useful comments; Dr Abdullah Al Mamun for his technical assistance. This work is supported by the Department of Food Service and Management, Universiti Putra Malaysia, Faculty of Entrepreneurship, Universiti Malaysia Kelantan and also the Ministry of Education, Malaysia.

\section{REFERENCES}

[1] W. Hutton, Authentic Recipes from Malaysia, Singapore: Periplus Editions (HK) Ltd., 2005.

[2] H. Salleh, Peoples and Traditions, Kuala Lumpur: Editions Didier Millet, 2006.

[3] F. E. Amuquandoh, "International tourists' concerns about traditional foods in Ghana," Journal of Hospitality and Tourism Management, vol. 18, pp. 1-9, 2011

[4] E. L. Pufall, A. Q. Jones, S. A. McEwen, C. Lyall, A. S. Peregrine, and V. L. Edge, "Perception of the importance of traditional country foods to the physical, mental, and spiritual health of Labrador Inuit," Arctic, vol. 64 , no. 2 , pp. $242-250,2011$

[5] W. Vue, C. Wolff, and K. Goto, "Hmong food helps us remember who we are: perspectives of food culture and health among Hmong with young children," Journal of Nutrition Education and Behavior, vol. 43, pp. 199-204, 2011

[6] K. Ganasegeran, S. A. A. Dubai, A. M. Qureshi, A. A. Alabed, R. Am, and S. M. Aljunid, "Social and psychological factors affectig eating habits among university students in a Malaysian medical school: a cross-sectional study," Nutrition Journal, vol. 11, no. 48, 2012.

[7] R. Muhammad, M. S. M. Zahari, and M. S. M. Sharif, "Impact of technology advancement on the Malaysian ethnic festival foods and its foodways," Procedia - Social and Behavioral Sciences, vol. 85, pp. 454-463, 2013.

[8] N. M. Nor, M. S. M. Sharif, M. S. M. Zahari, H. M. Salleh, N. Isha, and R. Muhammad, "The transmission modes of Malay traditional food knowledge within generations," Procedia - Social and Behavioral Sciences, vol. 50, pp. 79-88, 2012.

[9] V. Lopez, R. Corona, and R. Halfond, "Effects of gender, media influences, and traditional gender role orientation on disordered eating and appearance concerns among Latino adolescents," Journal of Adolescence, vol. 36, pp. 727-736, 2013.

[10] A. Forsyth, M. Wall, N. Larson, M. Story, and D. N. Sztainer, "Do adolescents who live or go to school near fast-food restaurants eat more frequently from fast-food restaurants?" Health and Place, vol. 18, pp. 1261-1269, 2012

[11] G.-J. D. Bruijn, S. P. J. Kremers, E. D. Vet, N. J. De, W. V. Mechelen, and J. Brug, "Does habit strength moderate the intention-behavior relationship in the Theory of Planned Behavior, the case of fruit consumption," Psychology and Health, vol. 22, no. 8, pp. 899-916, 2007.

[12] R. M. Rojas, C. Garita, M. Sanchez, and L. Munoz, "Barriers to and motivators for healthful eating as perceived by rural and urban Costa Rican adolescents," Society for Nutrition Education, vol. 37, pp. 33-40, 2005.

[13] P. M. Amos, F. D. Intiful, and L. Boateng, "Factors that were found to influence Ghanaian adolescents' eating habits," Sage Open, vol. 2, pp. $1-6,2012$.

[14] I. Ajzen, "The theory of planned behavior," Organizational Behavior and Human Decision Processes, vol. 50, pp. 179-211, 1991.

[15] M. S. M. Sharif, M. S. M. Zahari, N. M. Nor, and R. Muhammad, "Factors that restrict young generation to practice Malay traditional festive foods," Procedia - Social and Behavioral Sciences, vol. 101, pp. 239-247, 2013.

[16] V. Alibabic, I. Mujic, D. Rudic, M. Bajramovic, S. Jokic, and E. Sertovic, "Traditional diets of Bosnia and the representation of the traditional food in the cuisine field," Procedia - Social and Behavioral Sciences, vol. 46, pp. 1673-1678, 2012.

[17] A. Kimura, Y. Wada, K. Ohshima, Y. Yamaguchi, D. Tsuzuki, T. Oka, and I. Dan, "Eating habits in childhood relate to preference for traditional diets among young Japanese," Food Quality and Preferences, vol. 21, pp. 843-848, 2010.

[18] R. L. Jaenke, C. E. Collins, P. J. Morgan, D. R. Lubans, K. L. Saunders, and J. M. Warren, "The impact of school garden and cooking program on boys' and girls' fruit and vegetable preferences, taste rating, and intake," Health Education and Behavior, vol. 39, no. 2, pp. 131-141, 2012.

[19] R. M. Rojas, V. S. Castro, U. C. Ramos, C. M. Aragon and F. H. Raven, "Psychosocial factors influencing the frequency of fast-food consumption among urban and rural Costa Rican adolescents," Nutrition, vol. 29, 2013, pp. 1007-1012.

[20] S. Favalli, T. Skov and D. V. Byrne, "Sensory perception and understanding of food uniqueness: from the traditional to the novel," Food Research International, vol. 50, 2013, pp. 176-188.

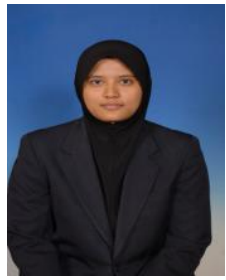

from 2011
Nur Hafizah Muhammad was born in Perak, one of the north states of Malaysia. She receives a bachelor's degree of science (hons) food studies from Universiti Putra Malaysia (UPM) in 2010, and is currently pursuing her master of science (food management) with research at Universiti Putra Malaysia (UPM). Her interest is in hospitality industry and consumer behaviors in food industry. She also serves as a tutor at Universiti Malaysia Kelantan (UMK) commencing 